\title{
Ten Years UK Experience in Survival for the Surgical Tavi Approaches
}

\author{
Francesca D’Auria ${ }^{1 *}$, Vincenzo Consalvo, Aung Myat, Uday Trivedi, David Hildick Smith \\ ${ }^{1}$ Brighton and Sussex University Hospital, Cardiac Surgery, UK
}

Submission: May 29, 2018; Published: June 14, 2018

*Corresponding author: Francesca D’Auria, Brighton and Sussex University Hospital, Cardiac Surgery, Barry Building, Eastern Rd, Brighton BN2 5BE, Brighton and Hove, UK, Email: f.dauria@hotmail.com

Abstract

Objectives: TAVI has expanded as alternative to surgical AVR, with well more than 250,000 patients treated worldwide since April $16^{\text {th }}$, 2002. The aim of this study is to compare Morbidity and Mortality (M\&M) associated with different surgical TAVI access alternative to the Surgical Femoral (SF).

Methods: 2,863 pts underwent surgical TAVI from Jan 2007 to Jan 2017 in the 33 UK TAVI Centers. Primary outcome is long-term survival up to Jul 2017. Secondary outcomes are procedural/in-hospital (in-H) complications (stroke, major vascular complications, bleeding, tamponade, permanent PMK, and renal replacement therapy), in-H, 30-day, and 1-year mortality. Statistical analysis by SPSS 20.0 (IBM Corporation, NY) and Stata 12.1 (Stata-Corp, College Station, TX). Continuous variables presented as median and interquartile range (25 to 75 percentile). Chi-square and Kruskal-Wallis test used as appropriate. Kaplan-Meier curve computed and a log-rank p value calculated. Cox proportional hazard model applied for primary outcome. P value $<0.001$ is significant.

Results: 2,863 pts, Surgical Femoral $(\mathrm{SF})=1,150+$ Trans Apical $(\mathrm{TA})=1,216+$ Direct Aortic $(\mathrm{DA})=207+$ Subclavian $(\mathrm{SC})=290$. In-H mortality lowest in SF (3.7\%, $n=43, p<0.0001$ vs pooled no-SF). Among the no-SF, only SC $(4.3 \%, n=12, p=0.69)$ not significantly different from SF, whereas TA $(9.5 \%, \mathrm{n}=116, \mathrm{p}<0.0001)$ and DA $(7.7 \%, \mathrm{n} 16, \mathrm{p}<0.02)$ associated with higher mortality. Unadjusted Kaplan-Meier survival chart showed long-term survival significantly greater in SC than DA and TA. No difference in survival between TA (1-year estimator 74.7 +/- $1.6 \%, p$ $<0.0001$ ) and DA (1-year estimator $75.2+/-3.3 \%$ ), both of which with significantly lower long-term survival than SF (1-year estimator 84.6 +/$0.7 \%, p<0.0001$ ). Unadjusted survival rate of the surgical SC cohort not significantly different from SF (1-year estimator $80.5+/-3 \%, p=0.27$ ).

Conclusion: This is the largest study to compare survival in surgical TAVI access routes using a large dataset retrieved from the UK TAVI registry. TA and DA were associated with almost similar survival, both significantly lower than after SC and SF. SC is the only non-SF approach for which survival was not significantly different from SF. It may represent the safest non-femoral access route for TAVI and it is the safest surgical route until now experienced.

Keywords: Aortic valve replacement; Trans catheter aortic valve implantation; Surgical TAVI; Minimally invasive surgery

\section{Introduction}

Transcatheter Aortic Valve Implantation (TAVI) has rapidly expanded as alternative to surgical aortic valve replacement, with well more than 250,000 patients treated worldwide since April 16th, 2002 [1-5]. Trial data are also extending into high, intermediate, and even low-risk operable patients. Trans Femoral (TF) approach is the default route for TAVI delivery [68]. However, small vessel caliper and/or peripheral vascular disease can preclude TF access in a significant cohort of patients. In the most recent trial investigating the new Edwards SAPIEN III valve, $36 \%$ of patients required non-femoral access. With the miniaturization in TAVI delivery systems, including the $14 \mathrm{Fr}$ Core Valve Evolut R, it is estimated that $10 \%$ to $15 \%$ of patients will still have unsuitable femoral access. Clinicians need to understand the relative outcomes of alternative nonfemoral access routes to guide optimal treatment of these patients [9-13].

Transapical (TA), Subclavian (SC), and most recently Direct Aortic (DA) access have developed as the principal alternatives to TF [14-15]. Although femoral access is routinely gained percutaneously by the operator, all nonfemoral access routes mandate a surgical cut-down to the apex of the heart, SC artery, or ascending aorta through a right-sided minithoracotomy or central mini or full sternotomy [16-20]. Previous studies have reported worse outcomes, including reduced survival, after nonfemoral TAVI [21-25]. However, very few data exist comparing the 
different nonfemoral access routes [26-35]. The aim of this study was to compare morbidity and mortality associated with different surgical access routes after TAVI.

\section{Methods}

The UK TAVI registry is a large prospectively collected database that includes $100 \%$ of patients who underwent TAVI in any of the 33 Centers performing TAVI procedures in the United Kingdom. It includes 8.320 patients who underwent TAVI from January 2007 to January 2017. All Centers use the same database as recommended by the National Institute for Cardiovascular Outcomes Research (NICOR). Data are collected in each hospital, electronically encrypted, and transferred online to the National Central Cardiac Audit Database (NCCAD). This algorithm allows for linkage to the National Health Service Central Registry, with all-cause mortality tracked for patients in England and Wales by unique National Health Service (NHS) number. Data collected include patient demographics, indications for TAVI, procedural characteristics, and adverse outcomes including complications up to the time of hospital discharge.

Survival is monitoredlong term. The primary outcome measure is long-term survival up to July 2017. Secondary outcome measures were procedural and in-hospital complications (including stroke, major vascular complications, bleeding, tamponade, permanent pacemaker implantation, and renal replacement therapy), and in-hospital, 30-day, and 1-year mortality. Statistical analyses have been performed using SPSS 20.0 (IBM Corporation, New York, New York) and Stata 12.1 (Stata-Corp, College Station, Texas). Continuous variables are presented as median and interquartile range (twenty-fifth to seventy-fifth percentile). The chi-square and Kruskal-Wallis test has been used as appropriate.

For survival analysis, a Kaplan-Meier curve was computed and a log-rank $\mathrm{p}$ value was calculated. A Cox proportional hazard model was applied for the primary outcome measure, corrected for EuroScore II, valve type, presence and severity of coronary artery disease, access route, heart rhythm, occurrence of post- procedural aortic regurgitation (assessed by echocardiography), and year of implantation. Covariates which were already incorporated into the EuroScore II (New York Heart Association and Canadian Cardiovascular Society class, age, gender, critical preoperative state, recent myocardial infarct, kidney failure, diabetes, extracardiac arteriopathy, previous cardiac surgery, chronic lung disease, LV function, and pulmonary hypertension) were not included as separate covariates into the Cox proportional hazard model.

Patients were matched 1:4 for the variables LogEuroScore II, body mass index, previous cardiac surgery, valve type, extracardiac arteriopathy, and year of implantation, and then a conditional logistic regression analysis was performed. A two-sided $\mathrm{p}$ value $<0.001$ was considered significant. This study complies with the Declaration of Helsinki. The data were collected as part of a mandatory UK National Cardiac Audit, and all patient-identifiable fields were removed before analysis. The National Institute for Cardiovascular Outcomes Research, which includes the UK TAVI registry, has support under section 251 of the National Health Service Act 2006. Ethical approval was not required under research governance arrangements for the analysis.

\section{Results}

In total, 8320 patients were registered in the UK TAVI database. Three patients who underwent TAVI through a carotid approach, 15 patients with missing information on access route were excluded. Finally, 8320 patients who underwent TAVI through TF (6588 patients: surgical $=1150-$ percutaneous $=5438)$, TA (1216 patients), DA (207 patients), and surgical SC (290 patients) were included. In hospital mortality was lowest in the surgical TF group $(3.7 \%, n=43, p<0.0001$ vs pooled non-TF). Among the nonfemoral access groups, only the surgical SC route $(4.3 \%, \mathrm{n}=12, \mathrm{p}$ $=0.69$ ) was not significantly different from surgical $\mathrm{TF}$, whereas TA (9.5\%, $\mathrm{n}=116, \mathrm{p}<0.0001)$ and DA $(7.7 \%, \mathrm{n} 16, \mathrm{p}<0.02)$ were associated with higher mortality. In hospital morbidity as per Valve Academic Research Consortium - 2 (VARC-2) criteria and mortality are summarized in Table 1.

Table 1: TAVI Outcome according to VARC - 2 criteria.

\begin{tabular}{|c|c|c|c|c|c|}
\hline Outcome & $\begin{array}{l}\text { Surgical Subclavian } \\
\text { (SC) } n=290\end{array}$ & $\begin{array}{c}\text { Transapical (TA) n } \\
=1216\end{array}$ & $\begin{array}{c}\text { Direct Aortic }(\mathrm{AD}) \mathrm{n} \\
=207\end{array}$ & $\begin{array}{c}\text { Surgical } \\
\text { Transfemoral(TF) } n \\
=1150\end{array}$ & $P$ Value \\
\hline In hospital death & $12(4.3 \%)$ & $116(9.5 \%)$ & $16(7.7 \%)$ & $43(3.7 \%)$ & $<0.0001$ \\
\hline 30-day mortality & $8(2.9 \%)$ & $134(11 \%)$ & $17(8.4 \%)$ & $54(4.7 \%)$ & $<0.0001$ \\
\hline 6-month mortality & $11(3.8 \%)$ & $182(15 \%)$ & 39 (19\%) & $59(5.1 \%)$ & $<0.0001$ \\
\hline 12-month mortality & $58(20 \%)$ & $328(27 \%)$ & $60(29 \%)$ & $207(18 \%)$ & $<0.0001$ \\
\hline In hospital TIA & $6(2.0 \%)$ & $12(1.0 \%)$ & 0 & $7(0.6 \%)$ & 0.22 \\
\hline In hospital stroke & $9(3.0 \%)$ & $36(3.0 \%)$ & $2(1.0 \%)$ & $24(2.1 \%)$ & 0.12 \\
\hline Tamponade & $6(2.0 \%)$ & $12(1.0 \%)$ & $2(1.0 \%)$ & $9(0.8 \%)$ & 0.07 \\
\hline $\begin{array}{c}\text { Vascolare } \\
\text { complication }\end{array}$ & $6(2.0 \%)$ & $5(0.4 \%)$ & $6(3.0 \%)$ & $40(3.5 \%)$ & $<0.0001$ \\
\hline
\end{tabular}


Journal of Anesthesia \& Intensive Care Medicine

\begin{tabular}{|c|c|c|c|c|c|}
\hline $\begin{array}{l}\text { Vascular surgery } \\
\text { repair }\end{array}$ & $6(2.0 \%)$ & $12(1.0 \%)$ & $4(2.0 \%)$ & $26(2.3 \%)$ & 0.59 \\
\hline Emergency V. in valve & $12(4.0 \%)$ & $12(1.0 \%)$ & $2(1.0 \%)$ & $31(2.7 \%)$ & 0.01 \\
\hline Haemofiltration & $12(4.0 \%)$ & $85(7.0 \%)$ & $21(10 \%)$ & $29(2.5 \%)$ & $<0.0001$ \\
\hline GI bleeding & $3(1.0 \%)$ & $24(2.0 \%)$ & 0 & $9(0.8 \%)$ & 0.01 \\
\hline PMK implantation & $67(23 \%)$ & $61(5.0 \%)$ & $15(7.0 \%)$ & 149 (13\%) & $<0.0001$ \\
\hline Hospital stay (days) & $7.0(5.0-10.0)$ & $8.0(5.0-15.0)$ & $8.0(5.0-16.0)$ & $5.5(4.0-8.0)$ & $<0.0001$ \\
\hline Follow up (days) & $609(312-994)$ & $567(225-1056)$ & $421(202-680)$ & $544(283-929)$ & $<0.0001$ \\
\hline
\end{tabular}

An unadjusted Kaplan-Meier survival chart was calculated which showed that long-term survival is significantly greater in SC group that DA and TA. It also showed that in DA group compared to TA group the long-term survival is equivalent. In effect, there was no difference in survival rate between TA (1-year estimator 74.7 $+/-1.6 \%, \mathrm{p}<0.0001)$ and DA (1-year estimator $75.2+/-3.3 \%$ ) approaches, both of which were associated with significantly lower long-term survival rate than surgical TF (1-year estimator $84.6+/-0.7 \%, p<0.0001)$. In contrast, unadjusted survival rate of the surgical SC cohort was not significantly different from surgical TF (1-year estimator $80.5+/-3 \%, p=0.27$ ). As the surgical SC route was the only non-femoral access route which was not significantly different from surgical TF on the Cox regression analysis, this finding was further confirmed using a propensitymatched population and a conditional logistic regression analysis which demonstrated a no-inferiority of the surgical SC route, if compared with the surgical TF access $(\mathrm{p}=0.86)$.

Considerable interest in complications is the hemofiltration which most commonly occurred in AD and TA TAVI procedures compared to surgical SC and surgical TF TAVI procedures. In contrast, the permanent pacemaker rate is greater in SC and TF TAVI procedures than in TA and DA TAVI procedures. Lastly, hospital average hospitalization is reduced in the surgical TF and SC TAVI group compared to TA and DA TAVI group. A comparison of the mortality trends and complications enumerated by the VARC criteria in the two quarters (2007-2008, 2008-2009, 2009-2010, 2010-2011, 2011-2012 vs. 2012-2013, 2013-2014, 2014-2015, 2015-2016, 2016-2017) was carried out. For each secondary outcome variable there is a marked improvement over the second five years compared to the results found in the first considered period.

In hospital mortality, 30 days, 6 months and 12 months, were significantly reduced over the period 2012-2017 compared to the 2007-2011 period. It should be pointed out that DA access in UK has been implemented since 2013, therefore the KaplanMeyer curves for 12 months survival are calculated from 2013 to 2017 and the comparison was performed between the periods 2013-2015 and 2016-2017. In the second five years, there is a remarkable reduction in patients who have to underwent renal replacement therapy. Among these two 5-years periods, the nodramatic reduction in cardiac tamponade is probably due to the increase in non-femoral access procedures which are indicated in patients with the highest risk profile. Vascular complication and GI bleeding were reduced in the second 5-years period compared to the first. It should be highlighted that through the two 5-years period, the rate of permanent pacemaker implantation is significantly reduced despite the increase in the Core Valve implantation (per se inherited by a higher rate of such complication). This indicates that the learning curve is the most weighted variable in this field. Finally, the average length of hospital stay is also reduced in the transition from the first 5-years period to the second period.

\section{Conclusion}

Despite progressive reduction in caliber of TAVI delivery systems, from initial 24Fr SAPIEN and 25Fr first-generation Core Valve to the $14 \mathrm{Fr}$ to $18 \mathrm{Fr}$ expandable e-sheath, $18 \mathrm{Fr}$ Core Valve, and 14Fr Evolut R systems available today on the market, a significant proportion of patients remain in whom small and/ or diseased vessels preclude a percutaneous TF approach. It is fundamental to understand the relative outcomes from alternative surgical approaches to guide optimal treatment for these clusters of patients who cannot receive benefit from percutaneous TAVI delivery. Because most Centers adopt a percutaneous approach and because those who underwent surgical access invariably have a worse risk profile, it is unclear to what extent worse outcomes relate to the patient rather than the procedure itself. More favorable result are achieved by single Centers performing highvolume surgical TAVI (i.e. TA), raising the possibility of a more significant learning curve or volume/outcome relation with the specific approach.

The present study found a TA approach to be associated with increased short-term and long-term mortality. Although precise factors behind the worse outcomes seen with TA and DA remain uncertain. For example in this study was observed that renal replacement therapy, a known predictor of increased mortality, was more frequently required with TA than SC. Compared to TA, the DA approach has the advantages of obviating separation of the pleura, so it may reduce postoperative pain and potentially respiratory complications. Potentially, this access route avoids injury to the left ventricular myocardium and there is to be observed that is a highly familiar procedure for each cardiac 
surgeon. Its use has rapidly expanded with both the Edwards SAPIEN and Medtronic Core Valve systems.

According to our knowledge, the present study reports the largest series of DA cases published so far and is the first study to compare DA, TA, SC and surgical TF approaches. We found no difference in both early and late mortality between DA and TA, with Kaplan-Meier survival curves almost superimposed. After multivariable analysis, both DA and TA were independent predictors of reduced survival. Although it is impossible to fully correct for differences in the DA and TA cohorts, a priori risk profiles (including Logistic Euro SCORE) appear similar, whereas the proximity of the unadjusted survival curves is striking. In contrast to TA and DA, both short- and long-term survival in patients who underwent TAVI through a SC approach were not significantly different from the surgical TF route, including after multivariable analysis.

Although the SC Kaplan-Meier survival curve was nearly superimposed on the TF curve up to 6 months, the survival graphs diverged thereafter. It is likely that late survival relates more to patient co-morbidities than the TAVI procedure, and the increased a priori risk of the SC cohort, reflected by the higher Logistic Euro SCORE, may explain the late separation of the curves. The explanation for the favorable outcome of SC in comparison with DA/TA remains uncertain. The surgical SC cutdown is less invasive than DA and TA access, leaving the chest cavity untouched. The requirement for and duration of general anesthesia, ventilation, and intensive care unit stay might be less. That the recovery process might be more favorable with SC is supported by the finding of the present study.

In fact, it showed that the median hospital stay was 1 day less than with TA and DA approaches. The main downside for SC in the present study was the high-rate of permanent pacemaker implantation, but it should be likely related to the predominant use of Core Valve for the SC approach. However, it is reassuring that pacemaker implantation after TAVI did not affect long-term survival. Despite the heterogeneity in the demographic data and significant differences in baseline characteristics between different access routes, the Logistic Euro SCORE and risk profile was very similar in the four surgical groups analyzed. In conclusion, this is the largest study to compare survival in surgical TAVI access routes in a real-world setting, using a large dataset retrieved from the UK TAVI registry. TA and DA approaches were associated with almost identical survival, both significantly lower than after surgical SC and TF TAVI. SC access was the only non-femoral approach for which survival was not significantly different from surgical TF. It may represent the safest non-femoral access route for TAVI and it is the safest surgical route until now experienced.

\section{Disclosure}

No conflict of interest declared by Authors.

\section{References}

1. Bonhoeffer P, Boudjemline Y, Saliba Z, Merckx J, Aggoun Y, et al. (2000) Percutaneous replacement of pulmonary valve in a right-ventricle to pulmonary-artery prosthetic conduit with valve dysfunction. Lancet 356(9239): 1403-1405.

2. Cribier A, Eltchaninoff $\mathrm{H}$, Bash A, Nicolas Borenstein, Christophe Tron, et al (2002). Percutaneous transcatheter implantation of an aortic valve prosthesis for calcific aortic stenosis: first human case description. Circulation 106: 3006-3008.

3. Cribier A, Savin T, Saoudi N, Rocha P, Berland J, et al. (1986) Percutaneous transluminal valvuloplasty of acquired aortic stenosis in elderly patients: an alternative to valve replacement? Lancet 1(8472): 63-67.

4. George I, Yerebakan H, Kalesan B, Nazif T, Kodali S, et al. (2014) Age alone should not preclude surgery: contemporary outcomes after aortic valve replacement in nonagenarians. J Thorac Cardiovasc Surg 148(4):1360-1369.

5. Sooknunden M, Radermecker MA, Defraigne J0, Tchana Sato V (2017) Surgical aortic valve replacement for stenosis of TAVI device. Acta Chir Belg 117(6): 401-403.

6. Kilic T, Yilmaz I (2017) Transcatheter aortic valve implantation: a revolution in the therapy of elderly and high-risk patients with severe aortic stenosis. J Geriatr Cardiol 14(3): 204-217.

7. Vahanian A, Alfieri O, Andreotti F, Manuel J Antunes, Gonzalo Barón Esquivias, et al. (2012) Guidelines on the management of valvular heart disease (version 2012). The Joint Task Force on the Management of Valvular Heart Disease of the European Society of Cardiology (ESC) and the European Association for Cardio-Thoracic Surgery (EACTS). Eur Heart J 33(19): 2451-2496.

8. Leon MB, Smith CR, Mack M, Miller DC, Moses JW, et al. (2010) PARTNER Trial Investigators. Transcatheter aortic-valve implantation for aortic stenosis in patients who cannot undergo surgery. N Engl J Med 363(17): 1597-1607.

9. Smith CR, Leon MB, Mack M, Miller DC, Moses JW, et al. (2011) PARTNER Trial Investigators. Transcatheter versus surgical aorticvalve replacement in high-risk patients. N Engl J Med 364(23): 21872198.

10. Makkar RR, Fontana GP, Jilaihawi H, Kapadia S, Pichard AD, et al. (2012) PARTNER Trial Investigators. Transcatheter aortic-valve replacement for inoperable severe aortic stenosis. N Engl J Med 366(18): 16961704 .

11. Kodali SK, Williams MR, Smith CR, Svensson LG, Webb JG, et al. (2012) PARTNER Trial Investigators. Two-year outcomes after transcatheter or surgical aortic-valve replacement. N Engl J Med 366(18): 16861695.

12. Auffret V, Bedossa M, Boulmier D, Verhoye JP, Ruggieri VG, et al. (2015) From FRANCE 2 to FRANCE TAVI: are indications, technique and results of transcatheter aortic valve replacement the same?. Presse Med 44(7-8): 752-760.

13. D'Errigo P, Barbanti M, Santini F, Grossi C, Ranucci M, et al. (2014) Gruppo di Lavoro dello Studio OBSERVANT. Results of the OBSERVANT study: clinical characteristics and short-term outcome of the enrolled population treated with transcatheter versus surgical aortic valve implantation. G Ital Cardiol (Rome) 15(3): 177-184.

14. Lipshutz AK, Feiner JR, Grimes B, Gropper MA (2016) Predicting mortality in the intensive care unit: a comparison of the University Health Consortium expected probability of mortality and the Mortality Prediction Model III. J Intensive Care 4: 35 
15. Shimura T, Yamamoto M, Kano S, Kagase A, Kodama A, et al. (2017) OCEAN-TAVI Investigators. Impact of the Clinical Frailty Scale on Outcomes After Transcatheter Aortic Valve Replacement. Circulation 135(21): 2013-2024.

16. Raheem S, Popma JJ (2012) Clinical studies assessing transcatheter aortic valve replacement. Methodist Debakey Cardiovasc J 8(2): 13-18.

17. Luc Piérard (2016) Transcatheter aortic valve implantation: indications. E-Journal of Cardiology Practice Vol.14, N¹-12.

18. Mack MJ, Holmes DR, Webb J, Cribier A, Kodali SK, et al. (2013) Patient selection for transcatheter aortic valve replacement. J Am Coll Cardiol 62(17): S1-S10.

19. Reardon MJ, Van Mieghem NM, Popma JJ, Kleiman NS, Søndergaard L, et al. (2017) SURTAVI Investigators. Surgical or Transcatheter Aortic-Valve Replacement in Intermediate-Risk Patients. N Engl J Med 376(14): 1321-1331.

20. Vinod H Thourani, Susheel Kodali, Raj R Makkar, Howard C Herrmann, Mathew Williams, et al. (2016) Transcatheter aortic valve replacement versus surgical valve replacement in intermediate-risk patients: a propensity score analysis. Lancet 387(10034): 2218-2225.

21. Thyregod HG, Søndergaard L, Ihlemann N, Franzen O, Andersen LW et al. (2013) The Nordic aortic valve intervention (NOTION) trial comparing transcatheter versus surgical valve implantation: study protocol for a randomised controlled trial. Trials 14: 11 .

22. Reardon MJ, Kleiman NS, Adams DH, Yakubov SJ, Coselli JS, et al. (2016) Outcomes in the Randomized CoreValve US Pivotal High Risk Trial in Patients With a Society of Thoracic Surgeons Risk Score of 7\% or Less. JAMA Cardiol 1(8): 945-949.

23. Nielsen HH, Klaaborg KE, Nissen H, Terp K, Mortensen PE, et al. (2012) A prospective, randomised trial of transapical transcatheter aortic valve implantation vs. surgical aortic valve replacement in operable elderly patients with aortic stenosis: the STACCATO trial. Euro Intervention 8(3): 383-389.

24. Davies H (1965) Catheter-mounted valve for temporary relief of aortic insufficiency. Lancet 285(7379): 250.

25. Moulopoulos SD, Anthopoulos L, Stamatelopoulos S, Stefadouros M (1971) Catheter-mounted aortic valves. Ann Thorac Surg 11(5): 423430

26. Phillips SJ, Ciborski M, Freed PS, Cascade PN, Jaron D (1976) A temporary catheter-tip aortic valve: hemodynamic effects on experimental acute aortic insufficiency. Ann Thorac Surg 21: 134-137.
27. Matsubara T, Yamazoe M, Tamura Y, Ohshima M, Yamazaki Y, et al. (1992) Balloon catheter with check valves for experimental relief of acute aortic regurgitation. Am Heart J 124(4): 1002-1008.

28. Andersen HR, Knudsen LL, Hasenkam JM (1992) Transluminal implantation of artificial heart valves. Description of a new expandable aortic valve and initial results with implantation by catheter technique in closed chest pigs. Eur Heart J 13(5): 704-708.

29. John G Webb, Ronald K Binder (2012) Transcatheter aortic valve implantation: The evolution of prostheses, delivery systems and approaches. Implantation de valves aortiques par voie percutanée: évolutions technologiques. Archives of Cardiovascular Diseases 105(3): 153-159.

30. Barili F, Freemantle N, Folliguet T, Muneretto C, De Bonis M, et al. (2017) The flaws in the detail of an observational study on transcatheter aortic valve implantation versus surgical aortic valve replacement in intermediate-risks patients. Eur J Cardiothorac Surg 51(6): 1031-1035

31. Toggweiler S, Leipsic J, Binder RK, Freeman M, Barbanti M, et al. (2013) Management of vascular access in transcatheter aortic valve replacement: part 1: basic anatomy, imaging, sheaths, wires, and access routes. JACC Cardiovasc Interv 6(7): 643-653.

32. Noble S (2013) Transapical aortic valve implantation: a reasonable therapeutic option, but not the only alternative to transfemoral approach. J Thorac Dis 5(3): 360-361.

33. Kappetein AP, Head SJ, Généreux P, Piazza N, van Mieghem NM, et al. (2012) Valve Academic Research Consortium-2. Updated standardized endpoint definitions for transcatheter aortic valve implantation: the Valve Academic Research Consortium-2 consensus document. Eur J Cardiothorac Surg 8(7): 782-795.

34. Kappetein AP, Head SJ, Généreux P, Piazza N, van Mieghem NM, et al. (2012) Updated standardized endpoint definitions for transcatheter aortic valve implantation: the Valve Academic Research Consortium-2 consensus document. Eur Heart J 33(19): 2403-2418.

35. Kappetein AP, Head SJ, Généreux P, Piazza N, van Mieghem NM, et al. (2012) Valve Academic Research Consortium (VARC)-2. Updated standardized endpoint definitions for transcatheter aortic valve implantation: the Valve Academic Research Consortium-2 consensus document (VARC-2). Eur J Cardiothorac Surg 42(5): S45-S60.
This work is licensed under Creative

Commons Attribution 4.0 License

DOI: 10.19080/JAICM.2018.06.555700
Your next submission with Juniper Publishers will reach you the below assets

- Quality Editorial service

- Swift Peer Review

- Reprints availability

- E-prints Service

- Manuscript Podcast for convenient understanding

- Global attainment for your research

- Manuscript accessibility in different formats

( Pdf, E-pub, Full Text, Audio)

- Unceasing customer service

Track the below URL for one-step submission https://juniperpublishers.com/online-submission.php 